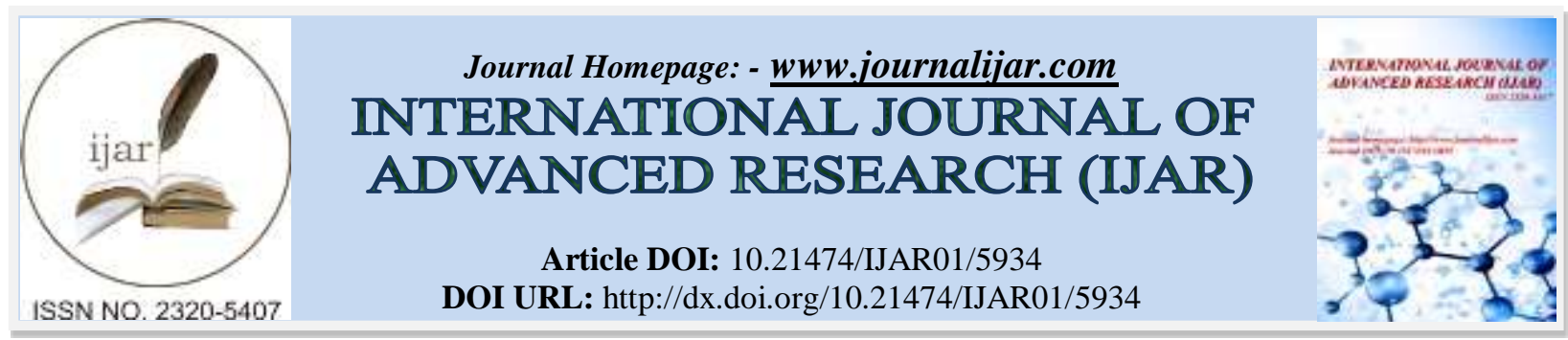

RESEARCH ARTICLE

\title{
TENSILE DEFORMATION BEHAVIOR AND FRACTURE OF FE-3.3\%SI STEEL AT A WIDE RANGE OF MODERATE TEMPERATURES.
}

\author{
Ruibin Mei ${ }^{1,2}$, Li Bao ${ }^{2}$, Guanglin $\mathrm{Li}^{3}$, Xin Zhang ${ }^{1,2}$, Xiwei $\mathrm{Qi}^{2}$ and Xianghua Liu ${ }^{1}$. \\ 1. State Key Laboratory of Rolling and Automation, Northeastern University, Shenyang 110819, PR China. \\ 2. Northeastern University at Qinhuangdao, Northeastern University, Qinhuangdao 066004, PR China. \\ 3. Ironmaking plant of Shougang Qian'an iron and steel Co Ltd, Qian'an 064404, PR China.
}

\section{Manuscript Info}

Manuscript History

Received: 01 October 2017

Final Accepted: 03 November 2017

Published: December 2017

\section{Key words:-}

tension, silicon steel, flow stress, fracture, moderate temperature.

\begin{abstract}
The flow stress behavior of hot-rolled $\mathrm{Fe}-3.3 \% \mathrm{Si}$ steel was studied through single-pass warm tensile experiments within the temperature range of 250 to $700{ }^{\circ} \mathrm{C}$ and strain rate range of 0.001 to $0.1 \mathrm{~s}^{-1}$. The fracture morphologies and microstructures were also examined after deformation. The peak stress decreased linearly, but the elongation increased exponentially, with an increase in temperature. Work hardening behavior was obvious, and the non-uniform plastic deformation stage was shorter at lower temperatures, and accordingly grains were elongated. Significant dynamic recovery and recrystallization occurring in the alloy at deformation temperatures up to $550{ }^{\circ} \mathrm{C}$ resulted in some equiaxed grains in the microstructure. Fractures were ductile at lower strain rates and higher tension temperatures. Quasi-cleavage fractures were generated at higher strain rates, and cleavage fractures were generated on different planes in the range from surface to center.
\end{abstract}

Copy Right, IJAR, 2017,. All rights reserved.

\section{Introduction:-}

As an important soft magnetic alloy, non-oriented silicon steel is widely applied in the power, electronic, and military industries. Many researchers have studied the improvement of microstructural and magnetic properties of non-oriented steel by varying chemical composition, heating and cooling technologies, rolling parameters, and annealing processes [1-4]. Fe-3.3\% Si steel is a high grade cold-rolled non-oriented electrical steel that exhibits obvious brittleness and poor cold-working ability [5]. Below the recrystallization temperature, recovery in metal forming occurs through an increase in the deformation temperature, which is helpful for the improvement of plastic deformation. For this reason, warm rolling is usually applied to silicon steel to improve its microstructural and magnetic properties [6-7]. The influence of the rolling parameters and deformation temperature on the texture and microstructure of non-oriented $\mathrm{Fe}-2.1 \% \mathrm{Si}$ steel during warm rolling processing was previously investigated by Zhang [8]. They found that the deformation texture changed from a shear texture at the surface to a planar texture at the center. Furthermore, shear banding occurred in the grains and the grains were elongated along the rolling direction at rolling temperatures of approximately $200-500{ }^{\circ} \mathrm{C}$. The deformation behavior at a moderate temperature is an important factor in the technological optimization of rolling processes, including cold and hot rolling.

The ductility of the magnetic material of Fe with $6.5 \mathrm{wt} \% \mathrm{Si}$ was previously investigated and its constitutive equation for warm deformation established by Li et al. [9]. Intergranular fractures could be transformed into quasi- 
cleavage fractures, which greatly improved the ductility of warm-rolled sheets at high rolling temperatures. The Johnson-Cook (JC) model was modified and employed by Zhang et al. [10] to predict the flow behavior of advanced high-strength steel at a wide range of temperatures from 298 to $1073 \mathrm{~K}$. The accuracy of the modified JC model was further verified, and the predicted flow stress was shown to be in good agreement with experimental results. Li et al. [11] investigated the warm deformation behavior of quenched $0.45 \mathrm{C}$ steel and established the corresponding constitutive equations.

Currently, despite many studies reporting on the improvement of microstructural and magnetic properties [12-14], few studies exist on the warm deformation behavior and fracture morphology of Fe-Si steel. In the present work, the warm deformation behavior of a hot-rolled Fe-3.3\% Si steel strip was therefore investigated using warm tensile experiments at a temperature range of approximately $250-700{ }^{\circ} \mathrm{C}$ and strain rate range of approximately $0.001-0.1 \mathrm{~s}^{-}$

1. Finally, fracture morphologies and microstructures were examined and analyzed using a scanning electron microscope (SEM). This study is of great importance for the study of the microstructure of silicon steel during warm rolling, as well as optimization of its rolling parameters.

\section{Materials and Methods:-}

The raw material in this study was a hot-rolled Fe-3.3\%Si steel strip from a plant with chemical composition as shown in Table 1.

Table 1:- Chemical composition of Fe-3.3\% Si steel.

\begin{tabular}{|l|l|l|l|l|l|l|l|l|}
\hline Element & $\mathrm{C}$ & $\mathrm{Fe}$ & $\mathrm{Si}$ & $\mathrm{Mn}$ & $\mathrm{Cu}$ & $\mathrm{S}$ & $\mathrm{Cr}$ & $\mathrm{Al}$ \\
\hline Contents & 0.0015 & 96.3 & 3.28 & 0.099 & 0.021 & $<0.009$ & 0.012 & 0.042 \\
\hline
\end{tabular}

The thickness of the original sample was $2.5 \mathrm{~mm}$, and standard tension specimens were cut with a total length of 200 $\mathrm{mm}$, parallel section length of $50 \mathrm{~mm}$, and gauge length of $30 \mathrm{~mm}$. A single-pass warm tensile test was carried out using an Inspekt Table $100 \mathrm{kN}$ (Hegewald\&Peschke, Germany) with samples at strain rates of $0.001,0.01$, and $0.1 \mathrm{~s}^{-}$ ${ }^{1}$, and deformation temperatures of $250,400,550$, and $700{ }^{\circ} \mathrm{C}$. Samples were first heated to their deformation temperature at $20{ }^{\circ} \mathrm{C} / \mathrm{min}$, and then the heat preservation time was 10 minutes in order to obtain a uniform temperature. The temperature was kept stable during all tensile processes. The oxide layer on the fracture surface of specimens was subsequently removed using ultrasonic equipment, and their fracture morphologies examined using a SUPRA 55 SEM (Zeiss, Germany). The used corrosion mixture was a mixture of $95 \%$ alcohol and $5 \% \mathrm{H}_{2} \mathrm{NO}_{3}$.

\section{Results and Discussions:-}

\subsection{Flow Stress}

The true stress-strain curves at different strain rates and temperatures are shown in figure 1. As can be seen, an increase in deformation temperature resulted in a significant decrease in peak stress and increase in elongation. Work hardening obviously occurred during metal forming at a deformation temperature of $250{ }^{\circ} \mathrm{C}$, with a shorter non-uniform plastic deformation stage. When the deformation temperatures were 250 and $400{ }^{\circ} \mathrm{C}$, samples rapidly underwent tensile breaking upon experiencing a stress greater than their peak stress, resulting in the obvious load drop. When the deformation temperature was $550{ }^{\circ} \mathrm{C}$, on the other hand, flow stress increased to peak value first due to the main effect of work hardening, after which the deformation distortion provided the driving force for dynamic recrystallization softening during continuous deformation, resulting in a subsequent slow decrease in flow stress. Increasing the strain rate had a smaller effect on the increase in stress at deformation temperatures of 250 and 400 ${ }^{\circ} \mathrm{C}$, because few slip systems exist at lower temperatures. 

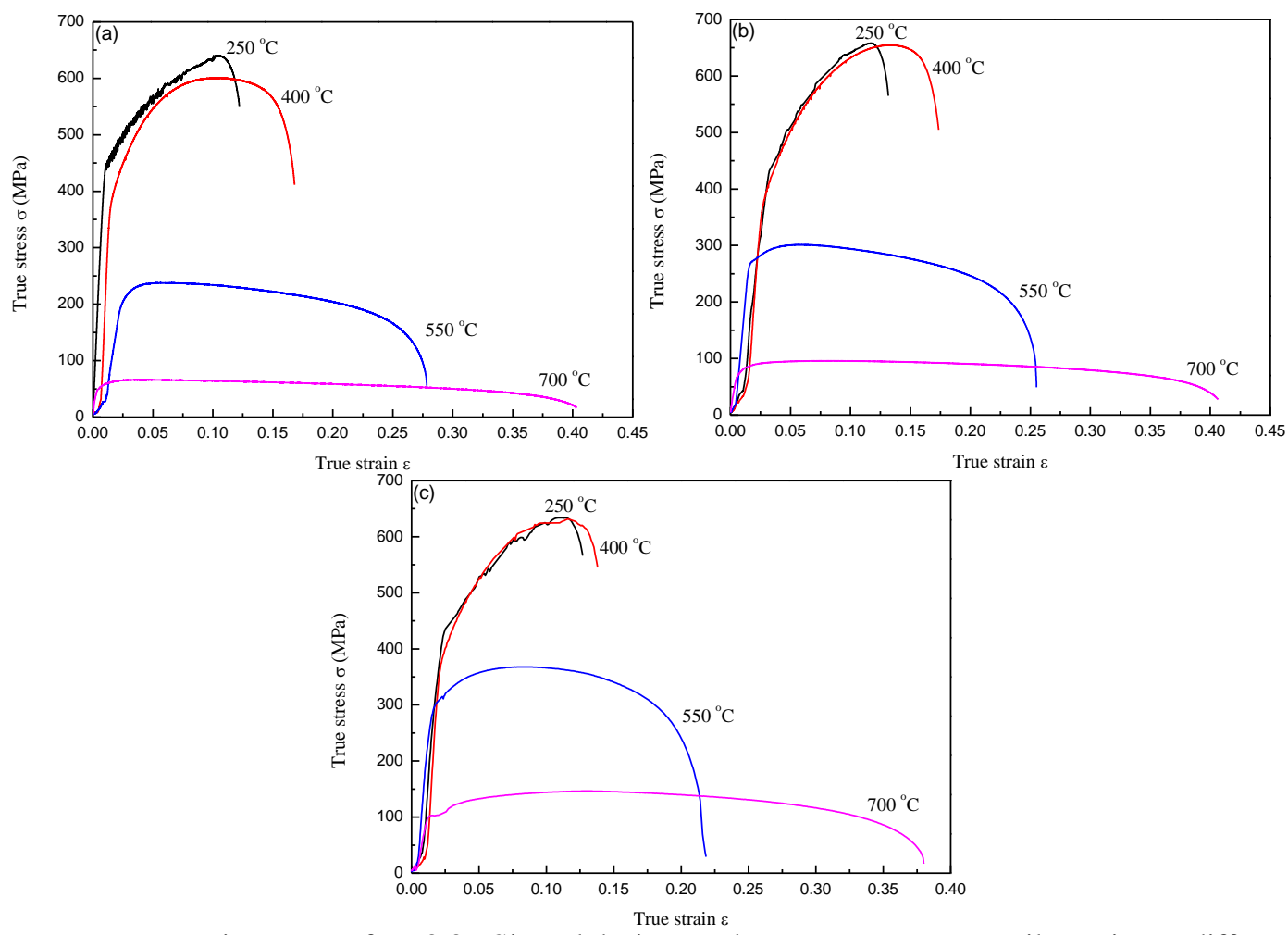

Fig. 1:- True stress-strain curves of $\mathrm{Fe}-3.3 \% \mathrm{Si}$ steel during moderate temperature tensile testing at different strain rates: (a) $0.001 \mathrm{~s}^{-1}$; (b) $0.01 \mathrm{~s}^{-1}$; (c) $0.1 \mathrm{~s}^{-1}$.

The measured peak stress and elongation values of Fe-3.3\% Si steel strips are shown in figure 2. The peak stress decrease approximated a linear function, especially within the deformation temperature range from 400 to $700{ }^{\circ} \mathrm{C}$. However, elongation increased exponentially with the increase in temperature, indicating that the increase in temperature is beneficial for plastic deformation. The effects of the strain rate on peak stress and elongation became more significant at higher temperatures than at $250{ }^{\circ} \mathrm{C}$. The reason for this might be that the slip system is not active at lower deformation temperatures. With an increase in strain rate, the dislocation movement was hindered from forming micro-cracks, so that peak stress increased, but elongation obviously decreased. Dynamic softening occurs more easily at higher deformation temperatures, which leads to a lower peak stress and higher elongation. Furthermore, lower strain rates allow sufficient time for dynamic softening processes to occur, especially at higher temperatures, and accordingly the tensile strength decreases and elongation increases significantly.
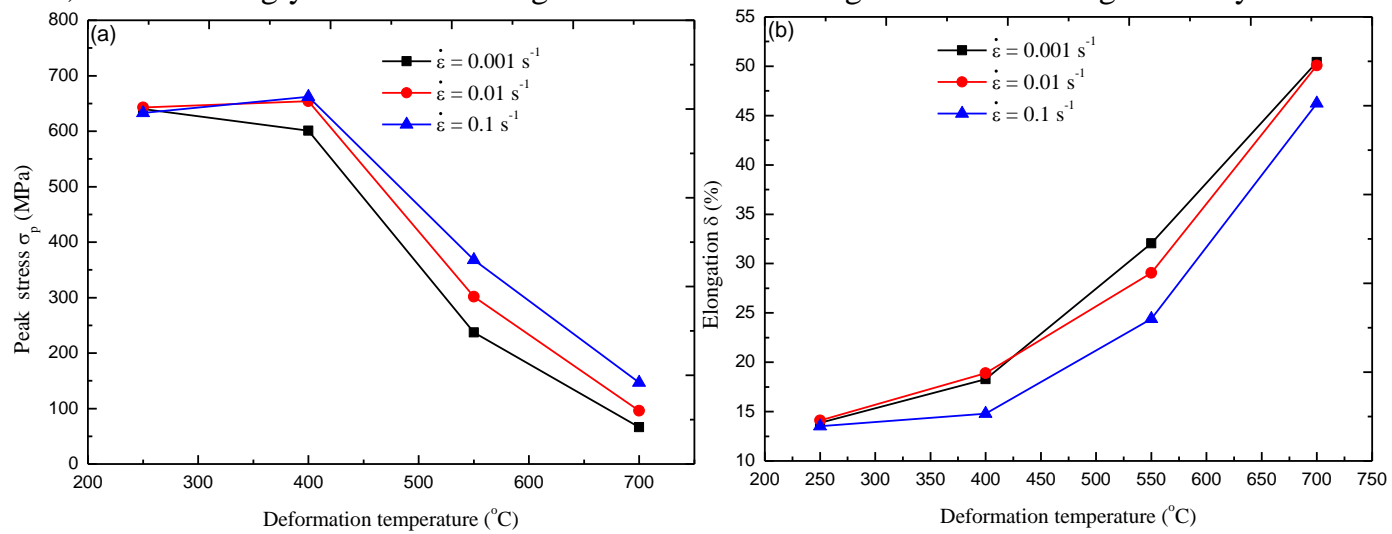

Fig. 2:- Peak stress and elongation of Fe-3.3\%Si steel: (a) peak stress; (b) elongation.

\subsection{Microstructure}

The microstructure of $\mathrm{Fe}-3.3 \% \mathrm{Si}$ steel was examined and analyzed, with the microstructures under different conditions shown in Fig. 3. As can be seen in Fig. 3(a), a host of deformation bands and small nucleated 
recrystallization grains existed after hot rolling. In spite of the grains being elongated in the direction of stretching when the deformation temperature was $250{ }^{\circ} \mathrm{C}$, the plastic deformation led to a small change in deformation band density and microstructure compared with the original material. When the deformation temperature was $550{ }^{\circ} \mathrm{C}$, dynamic recrystallization, occurring at the grain boundary, and the uniformity of the microstructure size were reduced. When the deformation temperature reached as high as $700{ }^{\circ} \mathrm{C}$, the finer equiaxed recrystallization grains generated in the vertical section and the deformation bands were gradually engulfed by the dynamic recrystallization grains. The surface metal flowed into the center and necking occurred in the non-uniform plastic deformation stage such that the strain in the center was larger than at the surface. At a strain rate of $0.1 \mathrm{~s}^{-1}$, it can be seen that dynamic recrystallization grains appeared in the deformation band at the center, and a number of equiaxed grains were generated at the surface.



Figure 3:- Microstructure of Fe-3.3\% Si steel at various conditions: (a) Original material; (b) $250{ }^{\circ} \mathrm{C}, 0.001 \mathrm{~s}-1$; (c) $400{ }^{\circ} \mathrm{C}, \quad 0.001 \mathrm{~s}-1$; (d) $550{ }^{\circ} \mathrm{C}, \quad 0.001 \mathrm{~s}-1$; (e) $700{ }^{\circ} \mathrm{C}, \quad 0.001 \mathrm{~s}-1$; (f) $700{ }^{\circ} \mathrm{C}, \quad 0.1 \mathrm{~s}-1$.

\subsection{Fracture Morphology}

The fracture morphologies using different tensile parameters are shown in Fig. 4. A dimple pattern can clearly be observed in the fractures at lower strain rates, which is characteristic of ductile fracture. The number and depth of 
dimples increased significantly at higher deformation temperatures, and as a consequence the ductility and fracture toughness of silicon steel were enhanced. The main reason for this might be that a higher temperature resulted in a higher thermal activation energy, while more mobile dislocation structures aggregated around inclusions, also leading to higher energy and more cavities. No apparent directionality could be observed in these dimples due to less plastic deformation at lower temperatures. The angle between the direction of the dimples and the vertical section was about $45^{\circ}$ at a deformation temperature of $550{ }^{\circ} \mathrm{C}$. Therefore, the fracture behavior was due to shear mechanisms. Plastic deformation clearly increased at $700{ }^{\circ} \mathrm{C}$ and $0.001 \mathrm{~s}^{-1}$ resulting from the increased dynamic recrystallization; the dimples had the same direction as the tension, and the maximum principle stress resulted in tensile fracture. Despite the larger size of some dimples at $550{ }^{\circ} \mathrm{C}$, the size and distribution of the dimples were more homogenous at $700{ }^{\circ} \mathrm{C}$, resulting in better plastic deformation ability. Furthermore, with the increase in strain rate there was not enough time to relax the deformation stress, generating micro-cracks on the crystal face; the fracture surface morphologies thus had river patterns and cleavage terraces, as seen in Fig. 4(b) and (d). Quasicleavage fractures were generated in different planes from the surface to the center at lower deformation temperatures and higher strain rates. Meanwhile, a multitude of dimples appeared among the layers of cleavage planes. The change in the relationship between the tensile stress, plastic deformation, and cracking, led to interactions between the maximum shear stress and principle stress on the normal direction of cleavage planes. Therefore, a higher rolling speed may not be beneficial for the plastic deformation of silicon steel during warm or cold rolling processes.
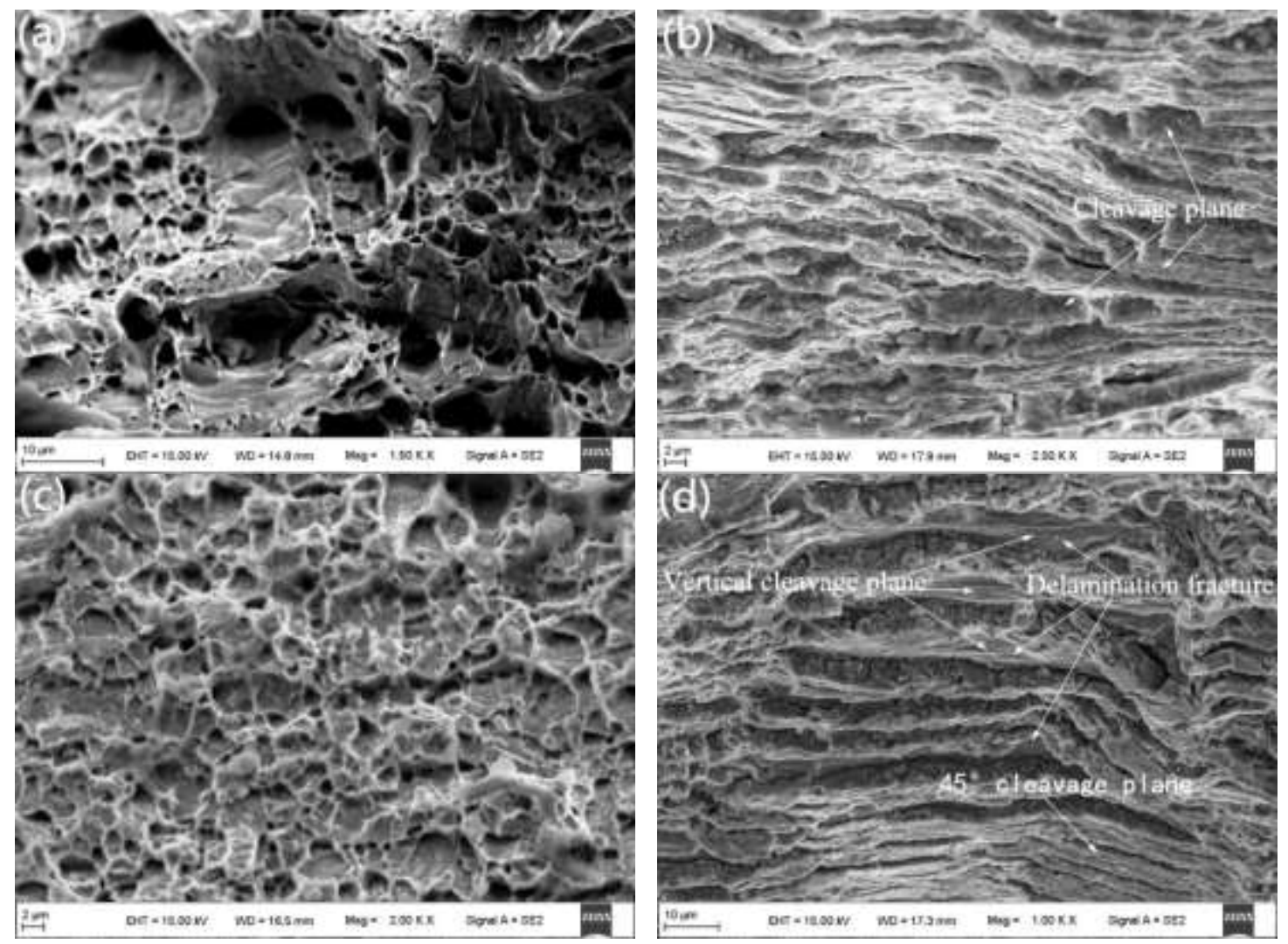

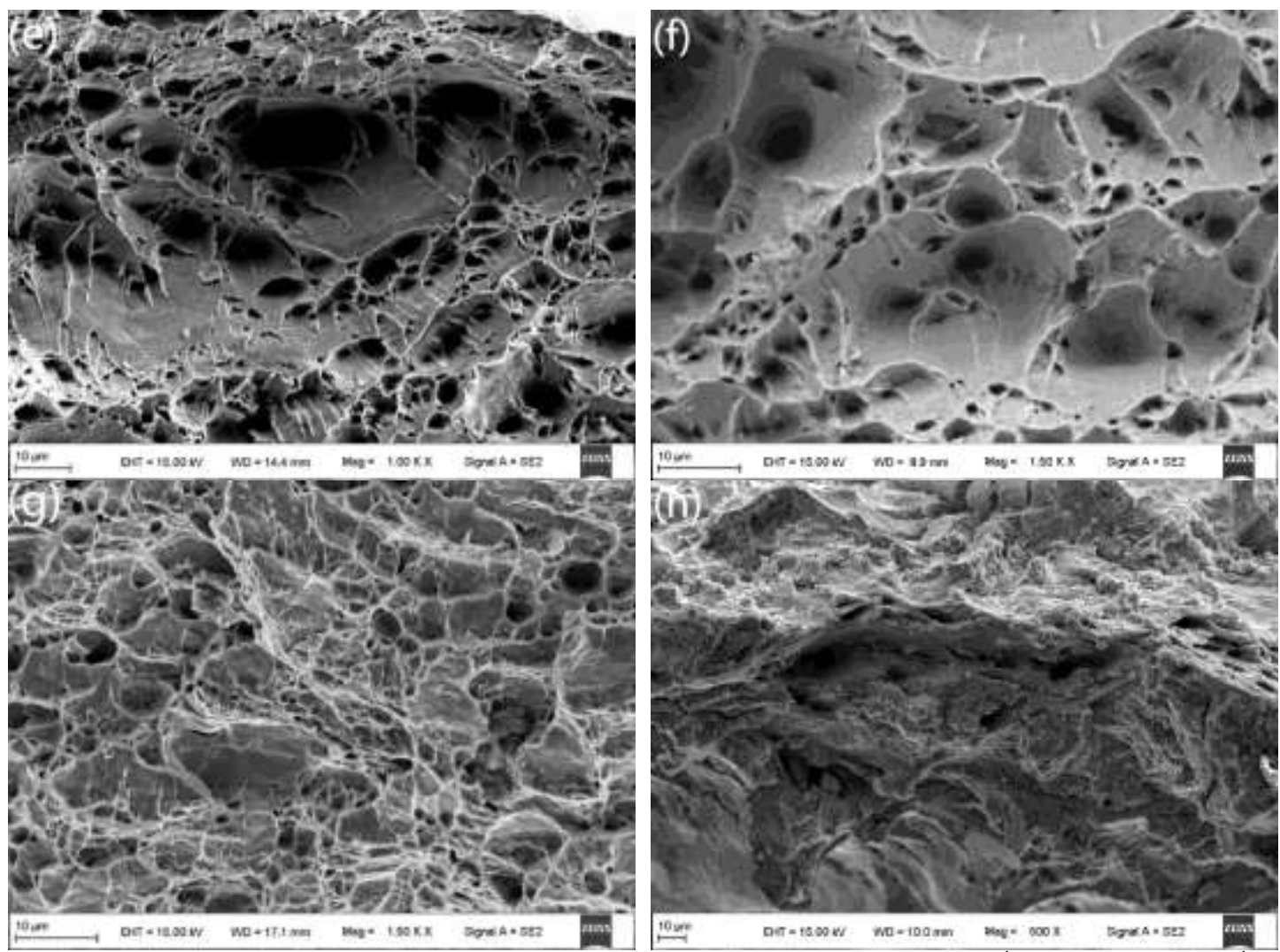

Figure 4:- Fracture morphologies for different tension parameters: (a) $250{ }^{\circ} \mathrm{C}, 0.001 \mathrm{~s}^{-1}$; (b) $250{ }^{\circ} \mathrm{C}, 0.1 \mathrm{~s}^{-1}$; (c) 400 ${ }^{\circ} \mathrm{C}, 0.001 \mathrm{~s}^{-1}$; (d) $400{ }^{\circ} \mathrm{C}, 0.1 \mathrm{~s}^{-1}$; (e) $550{ }^{\circ} \mathrm{C}, 0.001 \mathrm{~s}^{-1}$; (f) $550{ }^{\circ} \mathrm{C}, 0.1 \mathrm{~s}-1 ;$ (g) $700{ }^{\circ} \mathrm{C}, 0.001 \mathrm{~s}^{-1}$; (h) $700{ }^{\circ} \mathrm{C}, 0.1 \mathrm{~s}^{-1}$.

\section{Conclusions:-}

(1) Hot-rolled $\mathrm{Fe}-3.3 \% \mathrm{Si}$ steel was studied using tensile testing in the temperature range of $200-700{ }^{\circ} \mathrm{C}$ and strain rate range of 0.001-0.1 s $\mathrm{s}^{-1}$. Peak stress decreased linearly, but elongation increased exponentially with an increase in deformation temperature. Work hardening behavior obviously occurred and the non-uniform plastic deformation stage was shortened at lower temperatures.

(2) Although grains were stretched in the tensile direction at lower deformation temperatures the deformation bands density and microstructure changed little compared to those of the raw material. Dynamic recovery and recrystallization occurred at the grain boundary, and the uniformity of microstructure size was reduced at deformation temperatures up to $550^{\circ} \mathrm{C}$.

(3) Fracture morphologies exhibited significant dimple patterns at lower strain rates. The number and depth of those dimples significantly increased with an increase in deformation temperature, improving the plasticity and ductility. No apparent directionality existed in the dimples at lower temperatures, and the angle between the direction of dimples and the vertical section was approximately $45^{\circ}$ with an increase in temperature. Finally, quasi-cleavage fractures were generated in different planes from the surface to the center at lower deformation temperatures and higher strain rates, while a multitude of dimples appeared among the layers of cleavage planes.

\section{Acknowledgments:-}

The authors gratefully acknowledge financial support from the Natural Science Foundation-Steel and Iron Foundation of Hebei Province (No. E2014501114), the Science and Technological Youth Foundation of Hebei Higher (No. 20132007), the Doctoral Scientific Research Foundation of Liaoning Province (No. 20170520314), as well as the Fundamental Research Funds for the Central Universities (N152303013). 


\section{References:-}

1. Zhang W K, Mao W M, Wang Y D, et al. Influence of Hot Rolling Parameters on Microstructure and Magnetic Properties of Non-oriented Electrical Steel. Iron and Steel, 2006, 41(4):77-81.)

2. Yue E B, Li N. Effect of Rare Earth Cerium on the Magnetic Properties of 2.9\%Si Non-Oriented Electrical Steels. Iron and Steel, 2014, 49(1): 65-70.

3. de Dafe S S F, Paolinelli S D, Cota A B. Influence of thermomechanical processing on shear bands formation and magnetic properties of a $3 \%$ Si non-oriented electrical steel. Journal of Magnetism and Magnetic Materials, 2011, 323: 3234-3238.

4. Liu H T, Liu Z Y, Cao G M, et al. Microstructure and texture evolution of strip casting 3 wt $\%$ Si non-oriented silicon steel with columnar structure. Journal of Magnetism and Magnetic Materials, 2011, 323: 2648-2651.

5. Rodrigues M F, da Cunha M A, Paolinelli S D, et al. Texture and magnetic properties improvement of a 3\% Si non-oriented electrical steel by Sb addition. Journal of Magnetism and Magnetic Materials, 2013, 331: 24-27.

6. Nippon Kokan Kabushiki Kaisha, Sadakazu Masuda, Fumio Fujita, et al. Warm rolling method for high silicon steel strip : US, 0483809 [P/OL]. 1990-07-03.

7. Liu H T, Liu Z Y, Sun Y, et al. Development of $\lambda$-fiber recrystallization texture and magnetic property in $\mathrm{Fe}-$ $6.5 \mathrm{wt} \% \mathrm{Si}$ thin sheet produced by strip casting and warm rolling method. Materials Letters, 2013, 91:150-153.

8. Zhang G P. Influence of rolling gap geometry and temperature on the textures and microstructure of nonoriented electrical steel. Chinese Master's Theses Full-text Database: Engineering Science and Technology I, 2011, SI: 1-59.

9. Li C S, Cai G J, Cai B, et al. Impact of rolling temperature on microstructure, ordered phases, and ductility in Fe-6.5 wt\% Si magnetic material [J]. Journal of Materials Research, 2016, 31(19):1-12.

10. Zhang Q, Qiang C, Zhang X. A Modified Johnson-Cook Model for Advanced High-Strength Steels over a Wide Range of Temperatures. Journal of Materials Engineering and Performance, 2014, 23(12):4336-4341.

11. Li Q, Wang T S, Jing T F, et al. Warm deformation behavior of quenched medium carbon steel and its effect on microstructure and mechanical properties. Materials Science \& Engineering A, 2009, 515(1-2):38-42.

12. Perevertov $\mathrm{O}, \mathrm{Schafer} \mathrm{R}$. Magnetic properties and magnetic domain structure of grain-oriented $\mathrm{Fe}-3 \mathrm{Si}$ steel under compression. Materials Research Express. 2016, 3(9): 195-223.

13. Xiong $\mathrm{X}, \mathrm{Hu} \mathrm{S}, \mathrm{Hu} \mathrm{K}$, et al. Texture and magnetic property evolution of non-oriented Fe-Si steel due to mechanical cutting. Journal of Magnetism \& Magnetic Materials, 2015, 401: 982-990.

14. Bolfarini C, Silva M C A, Jr A M J, et al. Magnetic properties of spray-formed $\mathrm{Fe}-6.5 \% \mathrm{Si}$ and $\mathrm{Fe}-6.5 \% \mathrm{Si}-$ $1.0 \% \mathrm{Al}$ after rolling and heat treatment. Journal of Magnetism \& Magnetic Materials, 2008, 320(20): 653e656. 